\title{
EDUCAÇÃO AMBIENTAL POR MEIO DO TEATRO DE FLORESTA: UMA REFLEXÃO EM TORNO DAS AÇÕES DO INSTITUTO AMIGOS DA FLORESTA AMAZÔNICA NO MUNICÍPIO DE BENEVIDES NO ESTADO DO PARÁ
}

Josiane da Silva Sousa Mattos ${ }^{1}$ Antônio Rodrigues da Silva Júnior ${ }^{2}$ André Cutrim Carvalho ${ }^{3}$

Para citar este artículo puede utilizar el siguiente formato:

Josiane da Silva Sousa Mattos, Antônio Rodrigues da Silva Júnior y André Cutrim Carvalho (2020): "Educação ambiental por meio do teatro de Floresta: uma reflexão em torno das ações do instituto Amigos da Floresta Amazônica no município de Benevides no estado do Pará”, Revista DELOS, Vol 13 № 37 (diciembre 2020). En línea:

https://www.eumed.net/rev/delos/37/educacao-ambiental.html

\section{RESUMO}

No Brasil, a Educação Ambiental deve ser vista como um instrumento de (trans)formação social, que possibilita compreender as múltiplas complexidades contemporâneas da relação sociedade-natureza e de (re)construção de novos valores sociais, culturais, conhecimentos e atitudes voltadas para uma simetria com o meio ambiente. No Estado do Pará, há cerca de 18 anos, o Instituto Amigos da Floresta Amazônica (ASFLORA) desenvolve ações práticas em torno da Educação Ambiental em escolas do ensino infantil e fundamental no município de Benevides, por meio de um conjunto de atividades integradoras, com destaque para o teatro de floresta. Isso posto, o objetivo geral do presente artigo é analisar as ações no campo da educação ambiental realizadas pelo Instituto ASFLORA; além disso, a pesquisa pretende demonstrar como configuram-se as abordagens teóricas e, é claro, os métodos de avaliação dessas ações com o propósito de contribuir para a sua otimização. Do ponto de vista metodológico, o artigo assume um caráter misto de investigação, uma vez que envolve aspectos quantitativos ao destacar dados estatísticos das atividades realizadas e de alunos participantes do projeto; e qualitativo, dadas as indagações aos coordenadores pedagógicos e professores em relação às atividades do Instituto ASFLORA. A principal conclusão indica que através de uma Educação Ambiental mais crítica, torna-se possível superar as "armadilhas" paradigmáticas nos mais variados ambientes educativos, cujo processo de intervenção sobre a realidade e seus problemas socioambientais acabam por contribuir para uma cidadania ativa, tendo como principal finalidade a tentativa de reversão da grave crise socioambiental que está em curso.

Palavras-chave: educação ambiental; meio ambiente; Instituto ASFLORA; teatro de floresta.

\section{EDUCACIÓN AMBIENTAL A TRAVÉS DEL TEATRO FORESTAL: UNA REFLEXIÓN ALREDEDOR DE LAS ACCIONES DEL INSTITUTO AMIGOS DEL BOSQUE AMAZÓNICO EN EL MUNICIPIO DE BENÉVIDOS EN EL ESTADO DE PARÁ}

\section{RESUMEN}

\footnotetext{
${ }^{1}$ Especialista em Gestão Ambiental e Desenvolvimento Sustentável pela Escola Superior da Amazônia (ESAMAZ) e Diretora Social e de Comunicação do Instituto ASFLORA. E-mail: sousamattos28@gmail.com

${ }^{2}$ Mestre em Gestão de Riscos e Desastres Naturais na Amazônia pelo Instituto de Geociências (IG) da Universidade Federal do Pará (UFPA). Doutorando pelo Programa de Pós-Graduação em Geografia da UFPA. Professor dos Cursos de Pós-graduação em Gestão Ambiental e Desenvolvimento Sustentável e, também, de Gestão de Recursos Hídricos e Saúde Pública da Escola Superior da Amazônia (ESAMAZ). E-mail: silvajuniorgeo@yahoo.com.br

${ }^{3}$ Doutor em Desenvolvimento Econômico e Pós-Doutor em Economia pelo Instituto de Economia (IE) da Universidade Estadual de Campinas (UNICAMP). Professor-Pesquisador da Faculdade de Economia (FACECON) e do Programa de Pós-Graduação em Gestão de Recursos Naturais e Desenvolvimento Local na Amazônia (PPGEDAM) da UFPA. Email: andrecc83@gmail.com
} 
En Brasil, la Educación Ambiental debe ser vista como un instrumento de (trans)formación social, que permita comprender las múltiples complejidades contemporáneas de la relación sociedad-naturaleza y la (re) construcción de nuevos valores, saberes y actitudes sociales, culturales orientadas a una simetría con el medio ambiente. En el Estado de Pará, desde hace aproximadamente 18 años, el Instituto Amigos del Bosque Amazónico (ASFLORA) ha desarrollado acciones prácticas en torno a la Educación Ambiental en las escuelas primarias y primarias del municipio de Benevides, a través de un conjunto de actividades integradoras, con Destacar para el teatro forestal. Dicho esto, el objetivo general de este artículo es analizar las acciones en el campo de la educación ambiental que realiza el Instituto ASFLORA; Además, la investigación pretende demostrar cómo se configuran los enfoques teóricos y, por supuesto, los métodos de evaluación de estas acciones para contribuir a su optimización. Desde el punto de vista metodológico, el artículo asume un carácter mixto de investigación, ya que involucra aspectos cuantitativos al resaltar datos estadísticos de las actividades realizadas y de los estudiantes que participan en el proyecto; y cualitativo, dadas las consultas de los coordinadores pedagógicos y docentes en relación con las actividades del Instituto ASFLORA. La principal conclusión indica que a través de una Educación Ambiental más crítica, se hace posible superar las "trampas" paradigmáticas en los más variados entornos educativos, cuyo proceso de intervención sobre la realidad y sus problemáticas socio ambientales terminan contribuyendo a una ciudadanía activa, teniendo como El objetivo principal es el intento de revertir la grave crisis socio ambiental que se vive.

Palabras clave: educación ambiental; medio ambiente; Instituto ASFLORA; teatro forestal.

\title{
ENVIRONMENTAL EDUCATION THROUGH THE FOREST THEATER: A REFLECTION AROUND THE ACTIONS OF THE FRIENDS OF THE AMAZON FOREST INSTITUTE IN THE MUNICIPALITY OF BENEVIDES IN THE STATE OF PARÁ
}

\begin{abstract}
In Brazil, Environmental Education must be seen as an instrument of social (trans) formation, which makes it possible to understand the multiple contemporary complexities of the society-nature relationship and the (re) construction of new social, cultural values, knowledge and attitudes aimed at a symmetry with the environment. In the State of Pará, for about 18 years, the Friends of the Amazon Forest Institute (ASFLORA) has developed practical actions around Environmental Education in elementary and elementary schools in the municipality of Benevides, through a set of integrating activities, with highlight to the forest theater. That said, the general objective of this article is to analyze the actions in the field of environmental education carried out by ASFLORA Institute; in addition, the research intends to demonstrate how the theoretical approaches are configured and, of course, the methods of evaluation of these actions in order to contribute to their optimization. From a methodological point of view, the article assumes a mixed character of investigation, since it involves quantitative aspects by highlighting statistical data of the activities carried out and of students participating in the project; and qualitative, given the inquiries of pedagogical coordinators and teachers in relation to the activities of ASFLORA Institute. The main conclusion indicates that through a more critical Environmental Education, it becomes possible to overcome the paradigmatic "traps" in the most varied educational environments, whose intervention process on reality and its socioenvironmental problems end up contributing to an active citizenship, having as main purpose the attempt to reverse the serious socio-environmental crisis that is underway.

Keywords: Brazilian Amazon; Environmental education; ASFLORA Institute; Forest Theater.
\end{abstract}

Classificação JEL: Q01; Q30; Q56.

Classificação UNESCO: 530212; 530201; 530501.

\section{INTRODUÇÃO}

A terminologia "Educação" abrange um vasto campo de representações e encaminhamentos, seja para a qualificação profissional, mercado de trabalho, cidadania ou para o bom convívio social. Nesse vasto campo, um fator é comum, o fato que todos convergem para um entendimento universal, o de (trans)formação social.

Não é tão ingênua a banalização do antigo adágio popular que diz: "somente a educação é capaz de mudar os rumos de um país". Para Carvalho (2018: 02):

En ese sentido, las relaciones entre educación y desigualdad, evidentemente, remiten a múltiples y complejas dimensiones sociales, 
económicas y culturales". (...) Aunque el Estado brasileño en las últimas décadas ha logrado ampliar el acceso a la educación básica, las actuales evaluaciones han puesto en jaque la capacidad de nuestros sistemas educativos en ofrecer educación de calidad para la gran parte de la población que compone nuestra sociedad. En ese sentido, el gran desafío de este siglo es, sin duda, encontrar caminos que ecuen el binomio cantidad de vacantes y calidad en los establecimientos Escolares.

Mas é preciso ter (muita) prudência na difusão de certos modismos sem antes apropriar-se do que é considerado o mais importante neste processo: como estamos fazendo educação? Em que nível de educação? Para quem? Quais finalidades? Esses questionamentos são importantes para fugir das armadilhas do pragmatismo e da alienação do capital.

$\mathrm{Na}$ verdade, fazer educação é uma forma de construir pensamentos críticos, assim como como também políticas, culturas e atores sociais autônomos de suas convicções. É desse entendimento complexo do processo educativo que a sociedade deve iniciar seu processo de construção e reconstrução de modos de vidas que garantam a longevidade de sua sustentabilidade.

Por outro lado, emancipar culturas fortemente enraizadas na exploração de recursos naturais a qualquer custo, na transformação de produtos para consumo e no descarte cada vez maior e precoce não é uma tarefa fácil para educadores e tão pouco para a sociedade que vivencia este "estilo de vida" maciçamente.

A Educação Ambiental surge exatamente desse campo de reflexão sobre os modos e processos pelos quais nos relacionamos com o ambiente, entendido neste artigo como a junção indissociável da sociedade-natureza, no sentido de proporcionar à sociedade uma nova forma de relação, cuja dimensão ambiental seja vista como algo inerente ao desenvolvimento social e econômico.

De fato, é o esforço necessário que possibilita reflexões sociais em relação a sua própria realidade, suas ações, hábitos e costumes que passam a ser tratados como desafios, cujo entendimento holístico e interdisciplinar possibilita uma simetria nessa relação. Porém, como atentamente observado por Loureiro (2019), este processo é consideravelmente lento, uma vez que as relações sistêmicas capitalistas dinamizam comportamentos sociais incondizentes com a sustentabilidade do mundo contemporâneo, expressam múltiplas formas por diferentes países e universalizam sua dominância social do mundo.

Em decorrência dessa complexidade capitalista, que exige relações multidimensionais, que a perspectiva crítica deve ser tratada como uma corrente de Educação Ambiental fundamental para compreender e contribuir com a (trans)formação das diferentes sociedades, sob o método dialético, racional e histórico e como base em seu caráter contínuo e permanente, inerente a qualidade de vida.

Cabe dizer, neste momento, que aa Educação Ambiental não deve ser vista como uma ferramenta de resolução de problemas, tão pouco de longo alcance em meio a todas as perspectivas do ambientalismo, ou das utopias do desenvolvimento sustentável, mas é um viés aberto para o diálogo que possibilita transformações sociais, algo imprescindível para a emancipação e mudança no sistema, sobretudo em tempos de aumento da destruição dos recursos naturais na Amazônia brasileira.

Nessa ótica, a Educação Ambiental prevista na Lei Federal no 9.795/1999, precisa contemplar espaços formais e não formais de educação e atender públicos diversos, dinamizando o processo de ensino e aprendizagem e compartilhando experiências diversas. Daí a concordância com Loureiro (2019) em que não há um modelo de Educação Ambiental pronto como "receita de bolo", pois cada organização social possui suas singularidades e formas de se relacionar com o ambiente.

O Instituto Amigos da Floresta Amazônica (ASFLORA), objeto de estudo deste artigo, atua como agente de fortalecimento da árdua missão de fazer educação ambiental no Brasil, especialmente no Estado do Pará, ao explorar aspectos lúdicos da cultura Amazônica, cultura tão rica e ao mesmo tempo pouca explorada nos dias atuais.

O Instituto ASFLORA é uma entidade civil, de caráter técnico, científico e beneficente, sem fins lucrativos que tem como missão: educar, preservar, reflorestar e promover o intercâmbio de informações, tendo como princípio o desenvolvimento sustentável da região amazônica em suas dimensões ambientais, culturais, sociais e econômicas ${ }^{4}$. Desse modo, o instituto tem desenvolvido ações de educação ambiental tais como: palestras, ações culturais e campanhas de mobilização.

Em linhas gerais, as atividades desenvolvidas pelo Instituto ASFLORA com escolas de ensino fundamental do município de Benevides, Região Metropolitana de Belém no Estado do Pará,

\footnotetext{
${ }^{4}$ Essas informações foram extraídas da homepage oficial do Instituto ASFLORA. Link: http://asflora.org/asflora/quem-somos/
} 
procura discutir Educação Ambiental, predominantemente em sua vertente conservacionista e com alguns traços da perspectiva pragmática, por meio de palestras, visitas e trilha ecológica com apresentação do teatro de floresta, explorando lendas Amazônicas que fazem parte da cultura singular deste povo com a finalidade de construir uma nova relação sociedade-natureza.

O objetivo geral do presente artigo, portanto, é analisar as ações no campo da educação ambiental, realizadas pelo Instituto ASFLORA em três escolas de ensino infantil e fundamental do município de Benevides do Pará; além disso, a pesquisa pretende demonstrar como configuram-se as abordagens teóricas conceituais e, consequentemente, os métodos de avaliação dessas ações com o propósito de contribuir, de alguma forma, para a sua otimização.

Para isso, o presente artigo foi estruturado em cinco seções, além desta introdução. $\mathrm{Na}$ segunda é apresentada a metodologia empregada, com foco na caracterização da área de estudo, por se tratar de um estudo de caso e avaliação de ações; na terceira seção, discute-se a fundamentação teórica da educação ambiental, trazendo à baila um breve histórico da educação ambiental e suas implicações no Brasil ao aprofundar 0 debate sobre as concepções conservacionistas e pragmáticas à concepção crítica da educação ambiental; na quarta trata-se especificamente do instrumento de educação ambiental ao analisar o papel do teatro de floresta e do Instituto Amigos da Floresta Amazônica (ASFLORA), os resultados e discussões; na última as considerações finais.

\title{
2. METODOLOGIA: MATERIAL E MÉTODO
}

De acordo com Da Silva e Menezes (2005: 83): "a pesquisa é fundamentada e metodologicamente construída objetivando a resolução ou o esclarecimento de um problema. (...) da sua formulação dependerá o desenvolvimento da sua pesquisa". Minayo (2001: 16) prossegue: "A metodologia é o caminho do pensamento e a prática exercida na abordagem da realidade, ou seja, inclui as concepções teóricas de abordagem, o conjunto de técnicas e recursos que possibilitam a representação da realidade".

Para Lakatos e Marconi (1991: 106): "Os conhecimentos práticos estão submetidos à necessidade de conexão imediata com a realidade a que se referem". Partindo dessa concepção de metodologia, a presente pesquisa assume um caráter misto de investigação, uma vez que envolve aspectos quantitativos ao destacar dados estatísticos das atividades realizadas e de alunos participantes do projeto; e qualitativo, dada as indagações aos coordenadores pedagógicos e professores em relação às atividades do Instituto ASFLORA, ações e relações humanas que não se traduzem em operacionalizações matemáticas, mas, nomeadamente, pelo campo dos significados, que envolve observações, simbolismo, crença, sentimento, atitudes e outros atributos imensuráveis. Segundo Minayio (2001: 22):

\begin{abstract}
A diferença entre qualitativo-quantitativo é de natureza. Enquanto cientistas sociais que trabalham com estatística apreendem dos fenômenos apenas a região "visível, ecológica, morfológica e concreta", a abordagem qualitativa aprofunda-se no mundo dos significados das ações e relações humanas, um lado não perceptível e não captável em equações, médias e estatísticas. 0 conjunto de dados quantitativos e qualitativos, porém, não se opõem. Ao contrário, se complementam, pois a realidade abrangida por eles interage dinamicamente, excluindo qualquer dicotomia.
\end{abstract}

Como subsídios para a abordagem mista da pesquisa foi realizado um minucioso empoderamento teórico conceitual dos pressupostos da educação ambiental, considerando aspectos do construtivo histórico e epistemológicos, corroborando com uma reflexão crítica sobre a relação sociedade-natureza. Também foram aplicados questionários e entrevista semiestruturadas junto a coordenadores pedagógicos e professores das escolas municipais de Ensino Infantil e Fundamental Angélica de Souza Sales, São Francisco de Assis e Melquíades Costa de Lima, ambas localizadas no município de Benevides, região metropolitana de Belém, Estado do Pará, e que recebem as ações do Instituto ASFLORA.

Essas entrevistas contemplaram também, representantes do próprio Instituto ASFLORA, com a finalidade de verificar como se desenvolve as atividades junto aos alunos e levantar informações sobre métodos de avaliação das abordagens teóricas conceituais e de percepção das crianças em relação à compreensão de relação sociedade-natureza proposta pelo Instituto.

\subsection{Caracterização da área de estudo}


A pesquisa foi realizada no Instituto ASFLORA, como consta na Figura 1, e estendeu-se para as escolas municipais de ensino infantil e fundamental Melquíades Costa de Lima, Angélica de Souza Sales e São Francisco de Assis, ambas localizadas no município de Benevides, região metropolitana de Belém/PA, com alunos de quatro turmas do ensino infantil (05 anos de idade), duas turmas do ensino fundamental (06-08 anos de idade) e quatro turmas do ensino fundamental (09-14 anos de idade) no período de 2012 a 2017.

Ademais, outros dois critérios fundamentais foram considerados para a seleção dessas escolas e faixa etária dos alunos: o primeiro foi a frequência das ocorrências das ações, dada a prerrogativa da Educação Ambiental ser um processo indispensável e permanente para a formação cidadã; o segundo está ligado à faixa etária dos alunos, fator importante para observar qual o público essas ações manifestam maiores participações e interesses.

Figura 1 - Mapa de Localização do município de Benevides-PA e das escolas: São Francisco de Assis, Melquíades Costa de Lima e Angélica de Souza Sales

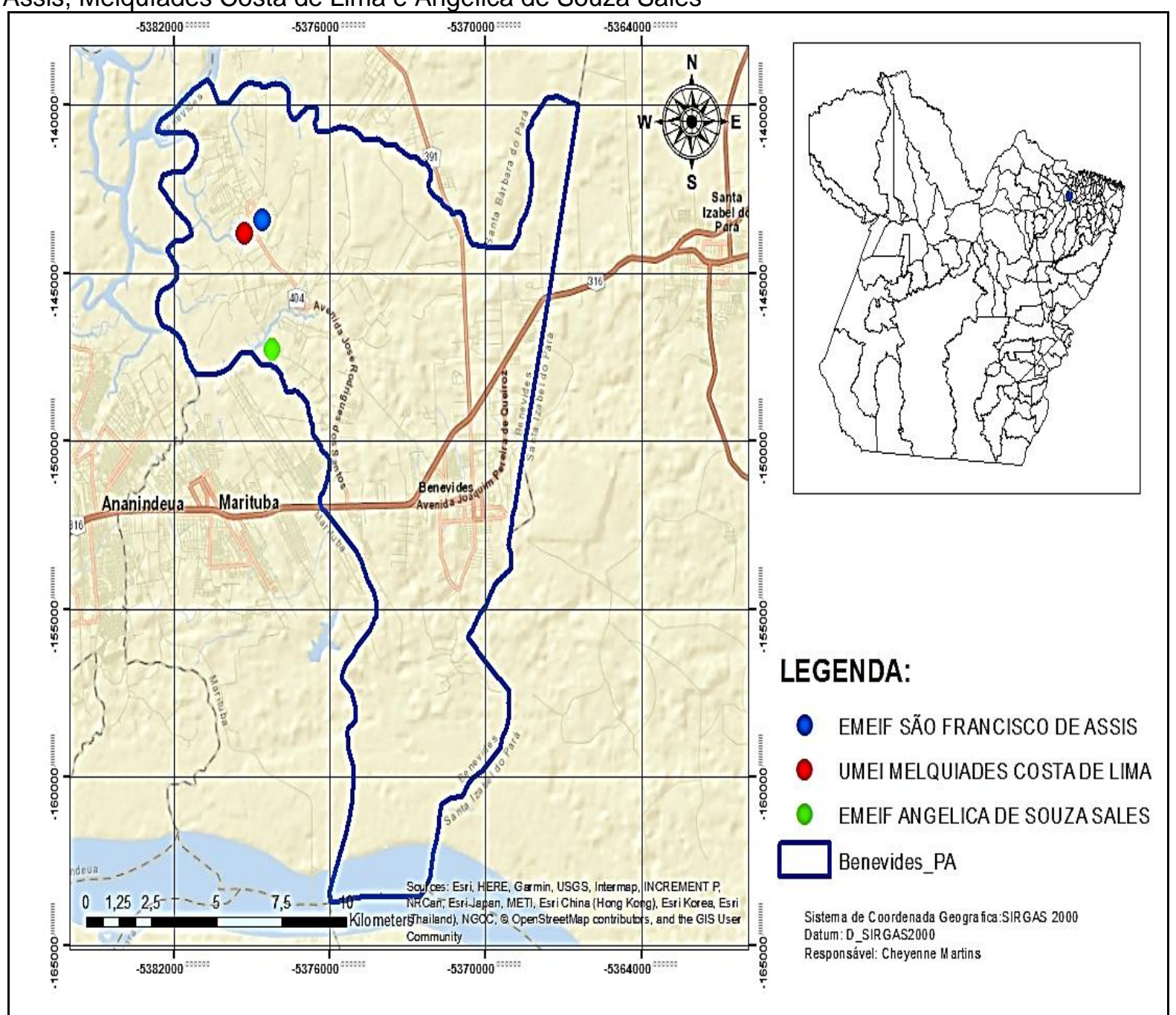

Fonte: Instituto Brasileiro de Geografia e Estatística/Sistema de Coordenada Geográfica, padrão Sistema de Referência Geocêntrico para as Américas, ano 2000 (IBGE/SIRGAS2000).

Na próxima seção será apresentado um breve histórico da Educação Ambiental e suas principais repercussões no Brasil. 


\title{
3. BREVE HISTÓRICO DA EDUCAÇÃO AMBIENTAL E SUAS IMPLICAÇÕES NO BRASIL
}

Do ponto de vista histórico, a questão ambiental emergiu das pressões e necessidade de discutir as formas de uso dos recursos naturais e das externalidades negativas dos sistemas de produção (capitalistas), propondo novas configurações de relações, cuja dimensão ambiental seja entendida como algo inerente à qualidade de vida. As suas discussões iniciais, no entanto, estavam (in)diretamente conectadas com o espaço natural, dissociando a participação humana do processo, algo que ganha novas dimensões a partir da compreensão sistêmica, onde o homem é visto como agente integrante e modelador do ambiente.

Os primeiros registros do emprego do termo "Educação Ambiental" datam a partir de 1948 quando de um encontro da União Internacional para a Conservação da Natureza (UICN) na cidade de Paris, França. Este termo foi fortalecido na Conferência em Educação, realizada na Universidade de Keele, Grã-Bretanha em 1965, assim como pelas primeiras discussões sobre as problemáticas ambientais, iniciadas pelo Clube de Roma em 1968, especialmente por meio do Relatório: "Os limites do crescimento" desenvolvido em 1972, onde as questões ambientais ganham dinamismo e se tornam um enfoque de estudo para muitas ciências. Nas palavras de Ramos (2001: 203):

\begin{abstract}
Alguns problemas eram cruciais como a ameaça do esgotamento dos recursos naturais, os efeitos da poluição ambiental, 0 crescimento populacional e o aumento da produção e do consumo. Era preciso impor, portanto, limites tanto para o crescimento e desenvolvimento econômico, como para o crescimento da população, já que os recursos naturais do meio ambiente passaram a ser vistos na sua crescente e ameaçadora finitude. A partir de então, a questão ecológica se impôs na agenda dos governantes dos países desenvolvidos dando início às grandes conferências e eventos internacionais para discutir os grandes problemas ambientais e a elaboração de propostas e estratégias de ação.
\end{abstract}

No entanto, foi na Conferência das Nações Unidas sobre o homem e o Meio Ambiente, realizada em Estocolmo na Suécia, no ano de 1972, o marco histórico das questões ambientais e da recomendação da Educação Ambiental. Ramos lembra (2001: 203-204):

Foi a primeira vez na história da humanidade que políticos, especialistas e autoridades de governo, representantes da sociedade civil e a ONU, se reuniram para discutir problemas ambientais na qual o meio ambiente foi colocado como tema principal da agenda em uma conferência oficial.

O referido autor continua (2001: 204):

Entre o rol de medidas analisadas, refletidas e recomendadas colocou-se, também, a responsabilidade do ser humano em sua relação com o ambiente, onde a educação adquire importância singular para a solução dos problemas. Manifesta-se a necessidade de mudança na intervenção do meio ambiente, e entende-se que isso é possível pela educação ambiental. Ocorre, assim, o primeiro pronunciamento oficial sobre a necessidade da EA em escala mundial, convertendo-se numa recomendação universal imprescindível, com a propagação de inúmeros projetos e programas para a sua implementação.

Em 1975, contudo, ocorreu o primeiro "Encontro Internacional sobre Educação Ambiental", realizado em Belgrado, capital da Sérvia no Sudeste da Europa, e contou com a participação de 65 países e teve como resultado a "Carta de Belgrado". De acordo com Dias (2013: 80): "(...) essa carta fortalecia as discussões iniciais sobre uma nova forma de exploração dos recursos naturais e que proporcionasse benefícios sociais, erradicando a pobreza, fome, analfabetismo, poluição e dominação e exploração humana".

A Conferência Intergovernamental sobre Educação Ambiental, realizada no ano de 1977 em Tbilisi na Geórgia, sob a organização da Organização das Nações Unidas para a Educação, a Ciência e a Cultura (UNESCO) em parceria com a ONU, foi considerada o marco mais importante da Educação Ambiental por ter dado prosseguimento no processo de difusão e institucionalização da Educação Ambiental no mundo.

Desse Conferência tem-se o desenvolvimento da primeira fase do intitulado: "Programa Internacional de Educação Ambiental", criado em Belgrado. Na visão de Dias (2013) foi um momento assaz importante, pois deliberaram-se os objetivos e características da Educação Ambiental, as estratégias a serem tomadas pelo programa e um chamamento para os países membros para incluíla na educação escolar. 
Cabe ressaltar a importância das demais conferências ambientais, sobretudo a Rio-92 onde foi assinado entre os países participantes o "Tratado de Educação Ambiental para Sociedades Sustentáveis e Responsabilidade Global" e a "Agenda 21".

Em suma, esses documentos estabeleceram os princípios fundamentais da educação para sociedades sustentáveis, destacando a necessidade de formação de um pensamento crítico, coletivo e solidário, que buscasse a interdisciplinaridade entre as ciências, de multiplicidade e diversidade, bem como lança um plano de ação para ser adotado pela sociedade não apenas em escala global ou nacional, mas também local.

Ademais, houve também a auto proclamada década da Educação para o Desenvolvimento Sustentável, no período 2005-2014, desenvolvida pela ONU, sob sete eixos temáticos: i) Cidadania, ii) Valores comunitários, iii) Diversidade, iv) Interdependência, v) Sustentabilidade, vi) Qualidade de vida e vii) Justiça social.

Tal ação representou um movimento importante que contribuiu com a potencialização das políticas, dos programas e das ações educacionais já existentes, além de multiplicar as oportunidades inovadoras. São desses contextos históricos, políticos e socioambientais que surgiram os instrumentos jurídicos legais (políticas ambientais) e as instituições ambientais no Brasil.

Isso fica evidente quando são analisadas as décadas de 1980 e 1990. Nesta periodização, observa-se o surgimento de marcos legais fundamentais que se evidenciam pela Política Nacional do Meio Ambiente - PNMA (Lei o 6.938/1981); pela inserção de artigo exclusivo para o meio ambiente na Constituição da República Federativa do Brasil de 1988; pelo Programa Nacional de Educação Ambiental -PRONEA de 1994; pela Lei de Diretrizes e Bases da Educação Nacional - LDB (Lei no 9.394/1996); pela Política Nacional dos Recursos Hídricos - PNRH (Lei no 9.433/1997); pela Lei de Crimes Ambientais (Lei no 9.605/1998); pela Política Nacional de Educação Ambiental - PNEA (Lei no 9.795/1999); e por meio de uma série de regulamentações do Instituto Brasileiro do Meio Ambiente e dos Recursos Naturais Renováveis - IBAMA (Lei no 7.735/1989).

Não é intenção do presente artigo ignorar a importância das legislações e das instituições ambientais que antecederam este contexto histórico, como aconteceu com o Código de Águas (1934), Código Florestal (1965), a Secretaria Especial de Meio Ambiente - SEMA (1973), dentre outros, mas sim evidenciar o avanço e as particularidades tomadas pela política ambiental brasileira. A partir disso, cabe sintetizar que a PNEA define Educação Ambiental como:

\footnotetext{
Um processo por meio do qual o indivíduo e a coletividade constroem valores sociais, conhecimentos, habilidades, atitudes e competências voltadas para a conservação do meio ambiente, bem de uso comum do povo, essencial à sadia qualidade de vida e sua sustentabilidade. Um componente essencial e permanente da educação nacional, devendo estar presente, de forma articulada, em todos os níveis e modalidades do processo educativo, em caráter formal e não formal (BRASIL, 1999).
}

Apesar do extenso desenvolvimento conceitual pari passu com esse amparo jurídico legal, no contexto da contemporaneidade, para desenvolver a Educação Ambiental no Brasil não se somou à este novo marco regulatório a diversidade, particularidade e realidade do país, em especial na Amazônia brasileira. O que se vê, ainda, é que este "novo" modelo segue, entretanto, vinculado às antigas formas de se fazer política pública no país, não de forma horizontal, mas vertical. Isso avulta múltiplas vertentes e tipos de entendimentos acerca da Educação Ambiental.

\subsection{Das concepções conservacionistas e pragmáticas à concepção crítica da Educação Ambiental: uma necessária reflexão}

Inicialmente, a complexidade da compreensão sociedade-natureza e a própria definição conceitual de Educação Ambiental fez com que suas abordagens tivessem um viés um tanto quanto naturalista, isto é, uma espécie de apelo por meio do radicalismo conservacionista e das relações biológicas de ecossistemas, uma visão reducionista que segundo Layrargues (2012) está vinculada à "pauta verde", por meio de atividades que contemplam a importância da natureza para a vida.

É desse contexto, por exemplo, que surgem as trilhas ecológicas e suas abordagens naturalistas, cujo homem é tratado somente como agente causador da destruição da natureza, sem qualquer conotação social que possa contemplar sua dimensão política, econômica e cultural.

Esse início tem muitas influências pautadas nas emergências ambientais, em que era preciso constituir mecanismos para desacelerar a exploração dos recursos naturais, pois os modos e meios operantes de produção em sua magnitude e velocidade de atuação colocariam o mundo em colapso. 
É, também, deste campo imediatista que a Educação Ambiental em sua vertente mais conservadora configura-se como uma proposta de preservação dos recursos naturais, da adoção de novas atitudes que repensam os modos consumistas sociais, pautados na ideia de reduzir, reutilizar e reciclar, bem como pelo contato e afetividade com o espaço natural.

Esta vertente adota a sociedade como seres desagregados de algo mais amplo e complexo, bem como enfatiza a educação, por meio da transmissão de conhecimento, como sendo suficiente para que ocorra a transformação do homem e, por conseguinte, adote novos hábitos e posturas com o ambiente. Como adverte Guimarães (2016: 16):

\begin{abstract}
Um projeto conservador de Educação baseado em uma visão liberal de mundo acredita que a transformação da sociedade é consequência da transformação de cada indivíduo, visto como seres em absoluta autonomia; a transformação depende da vontade individual. Desta forma, a Educação por si só é capaz de resolver todos os problemas da sociedade, basta ensinar 0 que é certo para cada um adquirir o comportamento correto, tornando-se assim uma Educação teórica, transmissora de informações e comportamentalista.
\end{abstract}

Pragmatismo significa o cumprimento de diretrizes ou ideais de boas relações em sociedade, emanadas de quem detém o poder de organização. Não ignorando as relações de poder econômico com o político, é necessário concentrar esforços à compreensão estritamente do poder econômico, cujo sistema capitalista hegemoniza as relações comerciais globais, bem como é o principal protagonista da vertente pragmática da Educação Ambiental até então.

Da compreensão resumida desta terminologia, é possível sintetizar o enfoque da Educação Ambiental Pragmática, como visto pelos autores Layrargues e Lima (2011), como uma tentativa ideológica do sistema capitalista de diluir os problemas socioambientais de sua produção, com a sociedade, sob o discurso paradoxo da sustentabilidade e se manter como dominante. Nestes termos, Guimarães (2016: 21) pondera:

Essa prática pedagógica presa à armadilha paradigmática não se apresenta
apta a fazer diferente e tende a reproduzir as concepções tradicionais do
processo educativo, baseadas nos paradigmas da sociedade moderna, sendo
esse um poderoso mecanismo de alienação ideológica e de manutenção da
hegemonia. Desta forma, essas práticas atreladas a essa armadilha, se
mostram pouco eficazes para intervir significativamente no processo de
transformação da realidade socioambiental, voltadas para a superação dos
problemas e a construção de uma nova sociedade ambientalmente
sustentável.

Layrargues (2012) classifica essa vertente da Educação Ambiental como hegemônica e a mais difundida na contemporaneidade, uma vez que suas ideologias estão obscuramente ancoradas no sistema econômico vigente, que propaga o discurso multidimensional de "preocupação ambiental", mas que ao mesmo tempo explora os recursos naturais e a força de trabalho em uma magnitude, intensidade e velocidade nunca antes visto.

Com um pressuposto metodológico dialético, relacional e histórico, a vertente da Educação Ambiental Crítica, porém, busca uma abordagem holística, sistêmica e interdisciplinar da relação sociedade-natureza, que seja capaz de contemplar suas múltiplas dimensões (política, econômica, social, cultural e ambiental), cuja ruptura do discurso paradigmático que assola os espaços de ensinoaprendizagem, a construção de uma racionalidade ambiental e a inserção da dimensão ambiental na dimensão econômica hegemônica são seus principais desafios.

Para Loureiro (2019), essa perspectiva crítica de Educação Ambiental, enquanto política, reconhece a diversidade e particularidades do povo brasileiro ao dar voz à eles. Além disso, o referido autor (2019) propõe, ainda, que o determinante, para fins de conhecimento da dinâmica social, é reconhecer que são as diferenças específicas de uma forma social que constituem as mediações sociais fundamentais, sem as quais não se consegue compreender as relações e as totalidades às quais pertencemos. Sobre essa questão, Guimarães (2016: 17) é incisivo:

Em uma concepção crítica de Educação, acredita-se que a transformação da sociedade é causa e consequência (relação dialética) da transformação de cada indivíduo, há uma reciprocidade dos processos no qual propicia a transformação de ambos. Nesta visão, educando e educador são agentes sociais que atuam no processo de transformações sociais e nesse processo se transformam; portanto, o ensino é teoria prática, é práxis. [...] Aqui a compreensão e atuação sobre as relações de poder que permeiam e 
estruturam a sociedade são priorizados, significando uma Educação política, a qual nos faz perceber e serem os sujeitos que somos na história.

A ruptura dessa armadilha ocorre a partir das práxis pedagógicas de reflexões críticas e, principalmente, da ação participativa de educando e dos educadores, que una de forma indissociável teoria e prática; reflexão e ação; razão e emoção; indivíduo e coletivo; escola e comunidade; local e global; em ambientes educativos resultantes de projetos pedagógicos que vivenciem o saber fazer criticamente consciente de intervenção na realidade, por práticas refletidas, problematizadoras e diferenciadoras, que se fazem politicamente influentes no exercício da cidadania, conforme dito por Guimarães (2016).

Partindo dessa concepção, compreender a Educação Ambiental para além das perspectivas naturalistas e da reprodução hegemônica do pragmatismo dominante nos discursos ambientalistas do capital, é um viés a ser tomado para uma possível emancipação, onde novas relações homemnatureza sejam intermediadas pela compreensão racional sobre os modos, produção e cultura de exploração e consumo que construímos, bem como, impliquem mudanças a níveis políticoseconômicos-sociais-culturais-ambientais.

$\mathrm{Na}$ realidade, a sociedade e a natureza apresentam o que Carvalho et al. (2017) denomina de "casamento" indissolúvel sob todos os aspectos, de tal forma que a destruição dos recursos naturais de um levará ao fim do outro (e vice-versa). Logo, é preciso pensar em um modelo de desenvolvimento que concilie eficiência econômica, equidade social e prudência ecológica, ou seja, o desenvolvimento sustentável.

\section{A IMPORTÂNCIA DO TEATRO DE FLORESTA COMO INSTRUMENTO DE DIFUSÃO DA EDUCAÇÃO AMBIENTAL SUSTENTÁVEL: O CASO DO INSTITUTO ASFLORA}

O Instituto ASFLORA é uma entidade civil, de caráter técnico-científico e beneficente, sem fins lucrativos, que fica localizado na rodovia BR-316, Km $25 \mathrm{~s} / \mathrm{n}$, Benevides, Pará, no Centro de Difusão Tecnológica (CDT) e Laboratório de Sementes e Mudas da Associação das Indústrias Exportadoras de Madeiras do estado do Pará (AIMEX)

A sua principal missão educar, preservar, reflorestar e promover o intercâmbio de informações tendo em seu princípio, o desenvolvimento sustentável da região amazônica em suas dimensões: ambiental, cultural, social e econômica (ASFLORA, 2018). Em 2004 foi criado pelo instituto um grupo teatral denominado "Teatro de Floresta", para trabalhar a educação ambiental em parcerias com escolas públicas e privadas, associações e sociedade em geral, nos municípios do Estado do Pará.

Com isso, o Instituto através desta ferramenta, emprega de forma lúdica o folclore amazônico mediante os protagonistas das fábulas culturais da região e, também, instrui sobre a importância da conservação do meio ambiente, propagando as potencialidades da Educação Ambiental como um caminho que possibilita (trans)formação social. O roteiro de suas ações compreende, pelo menos, três etapas do encontro com os alunos, à saber:

$1^{\circ}$ ) A primeira consiste em uma palestra temática sobre meio ambiente na sala de aula de apoio do ASFLORA, com média de tempo de quarenta e cinco (45) minutos e o uso de recursos áudio visuais. Esta palestra tem por finalidade o embasamento teórico dos alunos, considerando temáticas ambientais vivenciadas nas escolas e nos bairros onde estão situadas, para que consigam fazer relações com a atividade prática.

$2^{\circ}$ ) A segunda etapa consiste na visita dos alunos ao canteiro de mudas de vegetação nativa da Amazônia, com média de tempo de quarenta e cinco (45) minutos, onde ocorre a explicação do processo de cultivo das sementes, como são selecionados, como ocorre à quebra da dormência e a importância desse processo para obtermos mudas sadias e árvores de qualidade para serem utilizadas em áreas de reflorestamento. Ao final os alunos participam de semeio e/ou plantios de mudas.

$\left.3^{\circ}\right)$ A terceira e última etapa da atividade é a realização do "Tetro de Floresta", com média de tempo de sessenta (60) minutos baseada em roteiros técnicos previamente construídos pela equipe do Instituto, e ocorre em uma trilha ecológica situada na área da AIMEX, cujo os personagens vão surgindo cada um, em seu tempo dramatúrgico no decorrer do caminho, dialogando com o público sobre as formas de relação sociedade-natureza de forma dinâmica e criativa, instigando a interação dos alunos com os personagens. Esses personagens são atores voluntários que, durante as apresentações, ficam fantasiados com diferentes figurinos da cultura lúdica da região amazônica 
Ao final de toda a atividade tem-se uma breve conversa com o grupo de alunos e alunas, onde são feitos alguns questionamentos com o intuito de atestar o que foi assimilado dos temas abordados nas atividades em questão. É neste espaço que a educação ambiental é implementada. Sobre o papel da Educação Ambiental, Sorrentino et al. (2005: 288-289) afirma:

\begin{abstract}
A Educação Ambiental nasce como um processo educativo que conduz a um saber ambiental materializado nos valores éticos, e nas regras políticas de convívio social e de mercado, que implica também, na questão distributiva entre benefícios e prejuízos da apropriação e do uso indiscriminado da natureza. Ela deve, portanto, ser direcionada para a cidadania ativa considerando seu sentido de pertencimento e corresponsabilidade que, por meio da ação coletiva e organizada, busca a compreensão e a superação das causas estruturais e conjunturais dos problemas ambientais.
\end{abstract}

Percebe-se, desta forma, que para o melhor desenvolvimento desse processo educativo não existe métodos acabado-prontos, mas sim alguns direcionamentos de como abordar a complexidade ambiental, considerando modos singulares na relação sociedade-natureza e a observação comportamental dos atores sociais. Neste caso, de quais recursos metodológicos podem produzir melhores resultados no processo de ensino-aprendizagem, considerando modos de vida particulares.

Neste contexto, o "olhar" do professor/pesquisador/colaborador e a criatividade em explorar recursos metodológicos, que dinamizam e tornam o processo educacional mais acessível, é assaz importante na construção e no fortalecimento da Educação Ambiental.

O teatro de floresta do Instituto ASFLORA 5 , enquanto projeto, surgiu no ano de 2004 , como fruto da preocupação do instituto em educar ambientalmente crianças e adolescentes, para que através da experiência lúdica do teatro, seja semeada a conscientização necessária às futuras gerações, para que se desencadeiem os processos de construção de um futuro sustentável.

Nota-se que o teatro de floresta agrega os elementos necessários para sua difusão, tais como: inovação, cultura, roteiro crítico e realista; e, também, para o reconhecimento identitário ao demonstrar como as relações indissolúveis com a natureza podem ser intermediadas pela via da sustentabilidade ambiental.

Santos (2001: 33) destaca a integração de mecanismos e métodos, que são explanados através da apresentação de eventos teatrais, os quais desenvolvem concepções e práticas, que têm como finalidade construir saberes, atos e preceitos, trazendo uma reflexão sobre as ações do indivíduo em relação ao meio o qual se encontra:

\begin{abstract}
A educação através da arte desenvolve na pessoa aptidões de aprendizagem e de posicionamento sensível e crítico, que a tornam não só um agente transformador de si mesmo, mas também, de seu meio ambiente". Pois, o teatro proporciona o desencadeamento das ações, afeição e emoções, proporcionando cooperação mais efetiva dos educandos sobre os temas em debate, que buscam contribuir para uma mudança de consciência e atitudes no mundo concreto.
\end{abstract}

Silva e Sammarco (2004: 62) asseveram que "a arte-educação deve refletir o contexto social emergente, procurando sensibilizar para a mudança de atitudes de hábitos necessários de cada tempo/época". Com isso, o "Teatro de Floresta", através do reconhecimento e utilização dos elementos da linguagem dramática, tais como: espaço cênico, personagem e ação dramática, acabam por trabalhar com uma rede variada de assuntos destinados as questões ambientais, as quais estão diretamente relacionadas a realidades do contexto socioambiental dos seus telespectadores, como a sustentabilidade e a preservação da fauna, da flora, do meio ambiente da região amazônica, promovendo assim a educação ambiental que vai sendo trabalhada diretamente no processo de ensino dos problemas que atingem o meio ambiente de forma (in)direta como a poluição, desmatamento, degradação e destruição dos recursos naturais.

Fischer e Lummertz (2017) ao analisar as efetividades das intervenções da Educação Ambiental, utilizando o teatro como instrumento, observaram que o teatro instiga a reflexão ao permitir que os indivíduos enxerguem o mundo em múltiplos ângulos, levantando questionamentos e, assim, transformando-se em cidadãos autônomos, conscientes, críticos e protagonistas nas tomadas de decisões pautadas em valores coletivos em prol do bem-comum.

Os referidos autores (2017) observaram que a eficiência da ferramenta demanda, em primeiro lugar, um planejamento estruturado. Este, por sinal, deve considerar as realidades do seu público alvo ao utilizar linguagens que facilitem a compreensão da mensagem. Para tal, faz-se

\footnotetext{
${ }^{5}$ Maiores informações sobre o teatro de floresta do Instituto ASFLORA em: http://asflora.org/asflora/portfolio/teatro-de-floresta/
} 
necessário a união de educadores ambientais e outros atores, inclusive da sociedade civil organizada, para que o objetivo seja alcançado com êxito.

Logo, deve-se inserir na educação formal e não formal e em todos os níveis de ensino. Contudo, não apenas como uma simples matéria ou mesmo como uma forma de descontração, mas visando a integração com todas as disciplinas voltadas para as problemáticas reais. Para Araújo et al. (2019: 8) há um problema que acaba passando desapercebido:

Essa concepção errônea é resultado do déficit na educação formal, rígida e voltada apenas para a transmissão de conceitos, que desconsidera a importância das questões ambientais. Por conta disso, os cuidados com o meio ambiente estão cada vez mais escassos e mal direcionados. De fato a Educação Ambiental em espaços não formais, se faz necessária como forma não somente de sensibilizar, mas também de inserir o indivíduo em práticas que priorizem uma participação mais ativa em discussões e decisões sobre as questões ambientais.

Neste cenário, observa-se que o teatro está sendo trabalhado como uma ferramenta de cunho educativo, com uma vasta didática, pois esse recurso possibilita que o educando que esteja na plateia ou até mesmo nos bastidores, na equipe de apoio, ou atuando, seja impulsionado pela motivação e integração, permitindo a assimilação do conteúdo abordado com maior facilidade aprendendo através da ludicidade, a qual se revela como uma necessidade humana que não pode ser vista apenas como uma diversão, ressalta Spolin (2008).

Diante disso, é válido salientar a importância de se trabalhar a integração Educação Ambiental com o teatro, visto que, através do lúdico a aprendizagem torna-se uma práxis satisfatória, bem como, é um instrumento metodológico que tem um papel fundamental para construir, difundir e transformar pensamentos e atitudes comportamentais que contribuem para a construção da racionalidade ambiental.

\subsection{Resultados e discussões}

A pesquisa identificou que o Instituto ASFLORA realiza ações de Educação Ambiental com alunos das escolas municipais "Melquíades Costa de Lima", "Angélica de Souza Sales" e "São Francisco de Assis", desde o ano de 2012, através de parceria voluntária que partiu do próprio Instituto. Essas ações são uma espécie de integração por meio de palestras, visita(s) a canteiros de mudas e trilha ecológica, cujo o teatro de floresta é considerado a principal atração.

Todas essas ações ocorrem em um único dia na sede do Instituto, que possui uma logística estrutural que propicia o debate e as apresentações. Constatou-se que durante o período de 2012 a 2017, o Instituto ASFLORA realizou onze (11) ações nas referidas escolas contemplando mais de cento e sessenta e sete (167) alunos dinamizando e contribuindo com o processo de ensino aprendizagem através da Educação ambiental. (ASFLORA, 2018).

Para o Senhor Takushi Sato, presidente do Instituto ASFLORA, essas ações tem a finalidade e o potencial de transformação social, sobretudo de crianças e adolescente em pleno processo de formação cidadã. Ele destaca, entretanto, as dificuldades em tornar essas ações permanentes, pois não existem parcerias com entidades públicas ou privadas que oportunize bolsas de incentivos aos participantes do projeto, como ressaltado por ele:

Nossas ações de educação ambiental são destinadas aos alunos que estão em pleno processo de formação, são crianças e adolescentes que geralmente não tem esse tipo de diálogo em casa ou até mesmo nas escolas e acabam reproduzindo hábitos e atitudes errôneos postulados pelas influências do meio em que estão inseridos [...] Todavia, esse trabalho requer muita dedicação da equipe que fazem um esforço tremendo para compatibilizar suas obrigações pessoais com as ações do instituto, dada a falta de apoio dos poderes públicos e de iniciativas privadas ao projeto voluntário desenvolvido pelo ASFLORA. Mesmo com todas as dificuldades o instituto vem crescendo e se tornando referência na região metropolitana de Belém, graças a esses meninos e meninas que incansavelmente fazem da educação ambiental parte de seu dia a dia (Takushi Sato. Entrevista concedida em 13/03/2019).

Congrega com esta concepção a gestora da escola Melquiades Costa de Lima, a entrevista I. C. L. S., ao considerar que Teatro de Floresta contribui com o processo de ensino aprendizagem porque dinamiza as aulas que rotineiramente ocorrem em salas do ambiente escolar, bem como pelo 
seu aspecto lúdico com figurinos de personagens culturais do imaginário das lendas amazônicas, proporcionando maior atenção e admiração dos alunos, com reflexos positivos em sua formação enquanto cidadão. Para ela:

O teatro contribui com o processo de aprendizagem, conscientizando as crianças através da educação ambiental, de forma criativa e dinâmica, haja vista que a partir do momento que oportunizamos práticas diferenciadas, as nossas crianças se apropriam desse conhecimento [...] observei que muitas crianças aprenderam bastante com a apresentação, ficaram bem informadas sobre os riscos que o lixo causa na natureza e o que acontece com as árvores que são cortadas (I. C. L. S. Entrevista concedida em 08/03/2019).

Dessa mesma percepção, manifestam-se a Coordenadora pedagógica da escola São Francisco de Assis e uma das professoras da escola Angélica de Souza Sales, respectivamente, destacando a utilização da cultura regional para trabalhar a Educação Ambiental com adolescentes em formação. Na visão delas:

Esse teatro foi uma forma mais fácil de compreender o quanto a floresta, a água, o ar, os animais e as árvores são importantes para o meio ambiente e para os alunos, foi mais fácil as crianças compreenderem esse assunto que é tão importante para a nossa vida e para as próximas gerações. [...] teatro influenciou positivamente na visão do comportamento das nossas crianças, no que se refere à educação ambiental, principalmente sobre a questão do lixo, fortalecendo o que já trabalhamos em nossa escola, por meio de aulas e projetos (Coordenadora pedagógica R. S. C. Entrevista concedida em 08/03/2019).

Eu tenho certeza que todas as crianças ali presentes prestam atenção e aprendem o que cada apresentação expressa, entendendo a importância das sementes e seu processo para se formar belas árvores encontradas no meio ambiente (Professora A. F. Entrevista concedida em 13/03/2019).

Interessante notar o reconhecimento dos educadores em relação ao potencial do teatro de floresta, como recurso lúdico, para o processo de ensino-aprendizagem, algo que nem sempre é possível ou prazeroso nos modos convencionais de aula. Ainda assim, a comunidade reconhece que para fortalecer as prerrogativas do Art. 2ำ da PNEA ao destacar a Educação Ambiental como um processo que necessita de uma continuidade e permanência e que ocorra em espaços formais e não formais de ensino, é necessário expandir as ações do Instituto ASFLORA, uma vez que seus encontros acontecem de maneira não contínua, com um intervalo de tempo considerável.

Outra observação levantada é que essas ações ocorrem somente nas dependências do Instituto ASFLORA, não construindo um intercâmbio dos ambientes de ensino-aprendizagem.

As ações do ASFLORA precisam ser mais frequentes, e que não ocorra apenas na sede da instituição, mais que também possa vim até a escola, inclusive contemplar os pais dos alunos (Coordenadora Pedagógica da escola Melquiades Costa de Lima, E. N. N. Entrevista concedida em 08/03/2019).

Para fins de compreensão, alguns fatores que dificultam a realização de ações contínuas e o feedback com as escolas precisam ser pontuados, a exemplo das limitações do Instituto ASFLORA em relação a recurso financeiro, o pouco apoio do poder público pelo fato do trabalho ser voluntário. Nesse contexto, o registro das ações de educação ambiental do Instituto ASFLORA com alunos das escolas Melquíades Costa de Lima, Angélica de Souza Sales e São Francisco de Assis, no município de Benevides, está devidamente ilustrado por meio das Figuras 2(A), 2(B) e 2(C).

Figura 2(A), 2(B), 2(C) - Ações de Educação Ambiental do Instituto ASFLORA com alunos das escolas Melquíades Costa de Lima, Angélica de Souza Sales e São Francisco de Assis no município de Benevides: ano 2016 

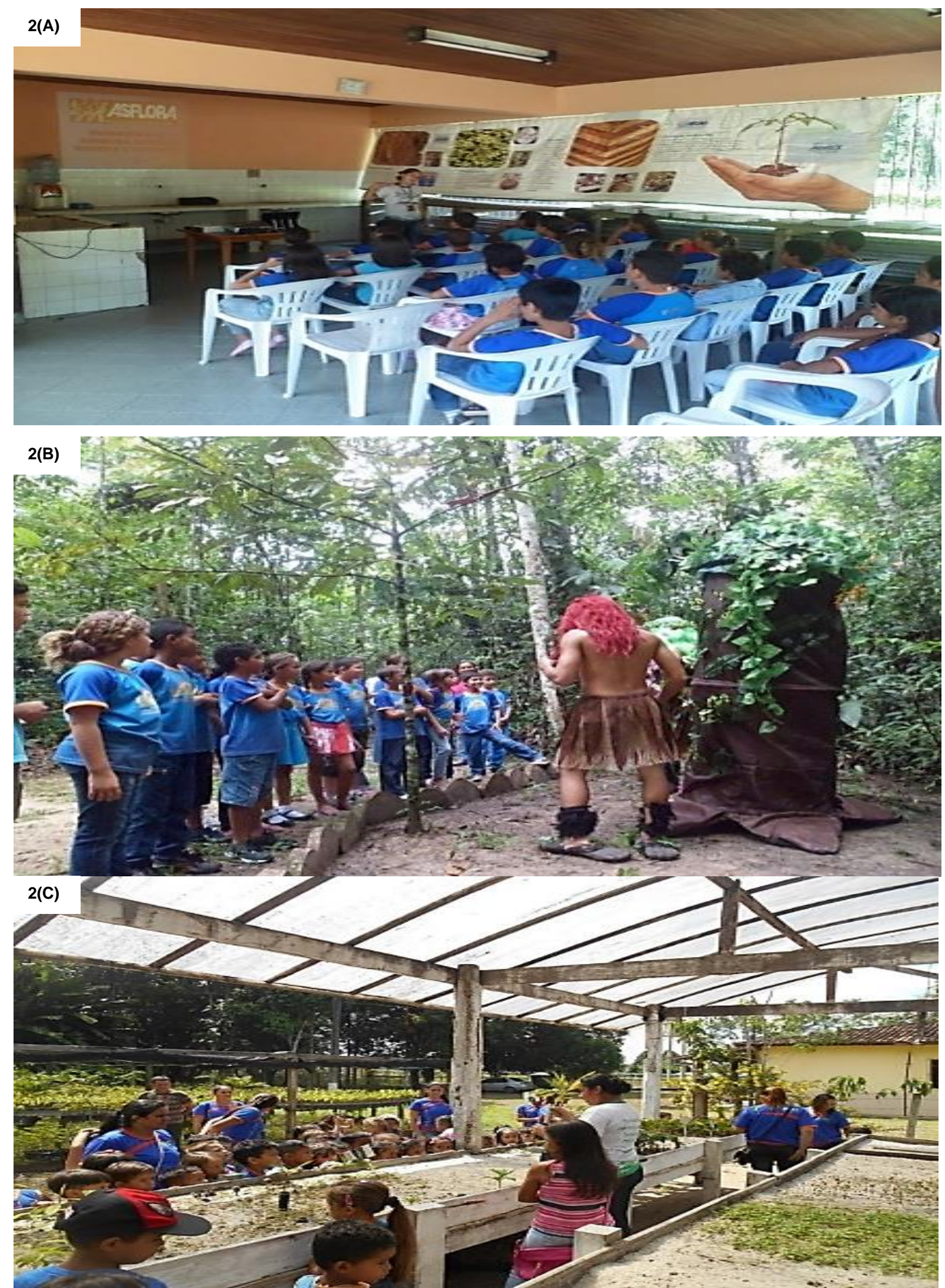

Fonte: Instituto ASFLORA, Ano 2016. ${ }^{\star} 2(\mathrm{~A})$ Palestra com temática ambiental: 2016; 2(B) Visita a canteiros de mudas de vegetação nativa: 2016; 2(C) Apresentação do teatro de floresta durante percurso de trilha ecológica: 2016

Os resultados obtidos confirmam que as ações do Instituto ASFLORA são positivas e bem aceitas pela comunidade estudantil, embora não sejam realizadas com a frequência desejada pelos professores e alunos. Em relação aos métodos de avaliação de suas atividades, constatou-se que 
esses se restringem a dados quantitativos e ao diálogo com os professores sobre a percepção dos alunos, no que concerne à participação, comportamentos e atitudes em relação à questão ambiental.

No momento, não existem outros instrumentos metodológicos que auxiliem o método quantitativo na avaliação dos resultados das ações, permanecendo essas no campo abstrato da percepção. Daí as dificuldades dos professores em avaliar qual público alvo, por faixa etária obteve melhor desempenho e assimilação das ações empregadas, muitas das vezes prevalecendo o "achismo" como foi relatado.

Além disso, foram identificados que os problemas vivenciados nas escolas possuem relações comuns com os bairros em que estão localizadas, entendidos pelos autores como reflexo da ausência ou precariedade das políticas (públicas) de educação no município, acarretando em hábitos e comportamentos não mais aceitos nas sociedades, que buscam o viés sustentável como qualidade de vida, e que as abordagens temáticas realizadas pelo Instituto ASFLORA sob essas problemáticas, contemplam, predominantemente, a vertente conservacionista da Educação Ambiental, reduzindo seu potencial crítico emancipatório do diálogo para além do naturalismo.

Para a análise da abordagem teórica conceitual e da vertente de educação ambiental trabalhada e sua dimensão, foi elaborado o Quadro 1 contendo os principais temas socioambientais abordados nas ações do Instituto ASFLORA, considerando a realidade vivenciada pelos alunos no ambiente escolar e na comunidade, respeitando os critérios adotados pelo Instituto ASFLORA.

Essas abordagens alimentam, ainda, traços da vertente pragmática ao fomentar o discurso da preocupação e responsabilidade ambiental sem abordar as premissas ideológicas do sistema capitalista hegemônico, que paralelamente ao discurso de preocupação ambiental, permanece explorando os recursos naturais numa velocidade nunca antes visto, causando perdas de qualidade de vida e difundindo culturas consumistas.

E mais, restringe suas discussões somente à dimensão social e ambiental, ao apresentar de maneira simplista a relação de exploração dos recursos naturais e as implicações dessa exploração para o homem e ao meio ambiente, excluindo desse sistema os elementos políticos, econômicos e culturais fundamentais para compreensão holística e sistêmica da Educação Ambiental.

Araújo et al. (2019: 9) observa que: "As práticas educativas ambientais devem assumir uma colocação perante a sociedade como agente transformadora. Além disso, deve tornar o indivíduo um agente social, tornando-o capaz de gerir - direta ou indiretamente - os recursos ambientais", pois estes passaram a ser o que Santos et al. (2014 apud Araujo et al. (2019: 9) denomina de "objetos essenciais" para a promoção do desenvolvimento sustentável.

\begin{tabular}{|c|c|c|c|c|c|c|}
\hline ESCOLAS & $\begin{array}{l}\text { PERÍODO } \\
\text { 2012- } 2017\end{array}$ & $\begin{array}{l}\text { PROBLEMAS } \\
\text { AMBIENTAIS } \\
\text { NA ESCOLA }\end{array}$ & $\begin{array}{l}\text { PROBLEMAS } \\
\text { AMBIENTAIS } \\
\text { NO BAIRRO }\end{array}$ & $\begin{array}{c}\text { AÇÕES DO } \\
\text { INSTITUTO } \\
\text { ASFLORA }\end{array}$ & $\begin{array}{l}\text { VERTENTE DA } \\
\text { EDUCAÇÃO } \\
\text { AMBIETNTAL } \\
\text { TRABALHADA } \\
\end{array}$ & DIMENSÃO \\
\hline $\begin{array}{l}\text { Angélica } \\
\text { de Souza } \\
\text { Sales }\end{array}$ & Três ações & Poluição visual & $\begin{array}{c}\text { Queima e } \\
\text { descarte } \\
\text { inadequado de } \\
\text { lixo }\end{array}$ & $\begin{array}{c}\text { Palestras } \\
\text { sobre } \\
\text { degradação } \\
\text { do } \\
\text { patrimônio } \\
\text { público, } \\
\text { resíduos } \\
\text { sólidos e } \\
\text { poluição } \\
\text { atmosférica; } \\
\text { visita a } \\
\text { canteiros de } \\
\text { mudas e } \\
\text { trilha com } \\
\text { teatro de } \\
\text { floresta }\end{array}$ & $\begin{array}{l}\text { Predominantemente } \\
\text { Conservacionista } \\
\text { com traços } \\
\text { pragmáticos }\end{array}$ & $\begin{array}{c}\text { Ambiental e } \\
\text { social }\end{array}$ \\
\hline $\begin{array}{c}\text { São } \\
\text { Francisco } \\
\text { de Assis }\end{array}$ & $\begin{array}{l}\text { Quatro } \\
\text { ações }\end{array}$ & $\begin{array}{l}\text { Lixo e poluição } \\
\text { visual }\end{array}$ & $\begin{array}{c}\text { Queima e } \\
\text { descarte } \\
\text { inadequado de } \\
\text { lixo }\end{array}$ & $\begin{array}{c}\text { Palestras } \\
\text { sobre } \\
\text { degradação } \\
\text { do } \\
\text { patrimônio } \\
\text { público, } \\
\text { resíduos }\end{array}$ & $\begin{array}{l}\text { Predominantemente } \\
\text { Conservacionista } \\
\text { com traços }\end{array}$ & $\begin{array}{l}\text { Ambiental e } \\
\text { social }\end{array}$ \\
\hline
\end{tabular}




\begin{tabular}{|c|c|c|c|c|c|c|}
\hline & & & & $\begin{array}{c}\text { sólidos e } \\
\text { poluição } \\
\text { atmosférica; } \\
\text { visita a } \\
\text { canteiros de } \\
\text { mudas e } \\
\text { trilha com } \\
\text { teatro de } \\
\text { floresta }\end{array}$ & pragmáticos & \\
\hline $\begin{array}{c}\text { Melquiades } \\
\text { Costa de } \\
\text { Lima }\end{array}$ & $\begin{array}{l}\text { Quatro } \\
\text { ações }\end{array}$ & Lixo & $\begin{array}{c}\text { Queima e } \\
\text { descarte } \\
\text { inadequado de } \\
\text { lixo }\end{array}$ & $\begin{array}{l}\text { Palestras } \\
\text { sobre } \\
\text { resíduos } \\
\text { sólidos e } \\
\text { poluição } \\
\text { atmosférica; } \\
\text { visita a } \\
\text { canteiros de } \\
\text { mudas e } \\
\text { trilha com } \\
\text { teatro de } \\
\text { floresta }\end{array}$ & $\begin{array}{c}\text { Predominantemente } \\
\text { Conservacionista } \\
\text { com traços } \\
\text { Pragmáticos }\end{array}$ & $\begin{array}{c}\text { Ambiental e } \\
\text { social }\end{array}$ \\
\hline
\end{tabular}

Quadro 1 - Análise das ações de Educação Ambiental do Instituto ASFLORA Fonte: Elaboração própria a partir da pesquisa no ano 2019.

Até porque a Educação Ambiental, como consta o inciso VI do $\$ 1^{\circ}$ do artigo 225 da Constituição Federal, deve ser estimulada em todos os níveis educacionais no Brasil. Nestes termos, como determina Brasil (1988), caberá ao Estado garantir a conscientização pública para a preservação do meio ambiente e evitar a destruição dos recursos naturais. Por isso, como adverte Araújo et al. (2019: 9), é preciso entender que:

(...) o meio ambiente é considerado um bem comum, pois é utilizado por todos e acima disto necessário aos seres humanos, ou seja, a sociedade possui o direito básico à educação nos níveis formais e não-formais, contudo, também, tem o dever de atuar em prol da preservação dos recursos naturais de modo geral.

Portanto, para que essas ações do Instituto ASFLORA sejam otimizadas e obtenham melhores resultados é necessário reavaliar sua metodologia de abordagem teórico conceitual, inserindo a perspectiva da Educação Ambiental crítica, que proporcionará uma discussão multidimensional, contemplando fatores indispensáveis para o diálogo ambiental, além de criar instrumentos de avaliação de desempenho de suas ações que vão além de dados quantitativos.

\section{CONSIDERAÇÕES FINAIS}

As ações de Educação Ambiental realizadas pelo Instituto ASFLORA nas escolas de ensino infantil e fundamental Melquiades Costa de Lima, Angélica de Souza Sales e São Francisco de Assis, do município de Benevides-PA, têm como finalidade educar crianças e adolescentes sobre a relação simétrica com o meio ambiente, por meio de palestras temáticas, visitas e contato com mudas da vegetação nativa e, sobretudo, pela apresentação lúdica do teatro de floresta que ocorre em trilha ecológica.

Essas ações possuem um potencial extremamente favorável ao processo de ensinoaprendizagem dos alunos, pois dinamizam a rotina das aulas em sala de aula e oportunizam a extensão da teoria ao campo, cujo contato, visualização e diálogo com o espaço, lugares e os atores sociais enriquece $o$ ensino.

Todavia, a Educação Ambiental possui potenciais muito maiores que os tratados pelo Instituto ASFLORA, que reduz praticamente suas abordagens à corrente conservacionista. Essas ações precisam contemplar também as discussões dialéticas presentes na vertente crítica da Educação Ambiental que proporcionará um diálogo mais amplo de compreensão de mundo, um universo, cuja abordagem sistêmica, interdisciplinar e holística é capaz de transformar cidadãos pelo empoderamento do conhecimento, e que leva o sujeito a refletir enquanto existência e na relação com o ambiente e seus elementos constituintes.

É necessário também, construir metodologias singulares, considerando a realidade vivenciada pela comunidade estudantil, e elaborar roteiros e planos de abordagens que fujam das amarras do pragmatismo e vai além do naturalismo, que consiga entender a Educação Ambiental, tal 
qual postula Reigota (2004), como educação política, reivindicatória, crítica e vigilante, que busca justiça social e cidadania plena na autogestão e ética no uso dos recursos naturais.

Outro fator importante é quanto à avaliação das ações do Instituto ASFLORA, que precisa ser considerada como fator indispensável neste processo, uma vez que podem apontar se a metodologia adotada está atendendo os objetivos do Instituto e que os resultados possam ser mensurados, perceptíveis e analisados.

Nesse aspecto, faz-se necessário ir além da quantificação das ações realizadas e escolas e alunos atendidos, bem como de percepções vagas. Na realidade, os instrumentos utilizados no âmbito da Educação Ambiental como a aplicação de uma avaliação objetiva, antes e após cada ação para avaliar o nível de assimilação das atividades, e a interação dos alunos com os personagens e roteiros do teatro de floresta, por meio de inversão de papéis; ou retratação da peça através de confecção e montagem de quebra-cabeça pelos alunos, são exemplos de grande relevância para fugir do campo metafísico da observação de comportamento.

É importante também que as escolas não sejam meros coadjuvantes desse processo educacional, e passem a construir de maneira conjunta com o Instituto ASFLORA outros métodos para avaliar as ações, bem como participar do planejamento das abordagens teóricas e conceituais dos temas abordados.

Percebe-se que por intermédio de uma Educação Ambiental mais completa, torna-se possível superar as "armadilhas" paradigmáticas nos mais variados ambientes educativos, cujo processo de intervenção sobre a realidade e seus problemas socioambientais acabam por contribuir para uma cidadania ativa, tendo como principal objetivo a tentativa de reversão da grave crise socioambiental que vivenciamos, caracterizada em outras palavras como sendo uma Educação Ambiental crítica.

De fato, a educação ambiental deve assumir o seu protagonismo ante os problemas e desafios que se apresentam na sociedade, ou seja, deve atuar, acima de tudo, como um agente de transformação social capaz de gerir (in)diretamente os recursos naturais em prol da promoção da sustentabilidade ecológica.

Enfim, é reconhecido o potencial das ações e o respeitável trabalho voluntário desempenhado pelo Instituto ASFLORA, algo tão incomum na contemporaneidade e assaz importante em tempos de pandemia e destruição ambiental. As considerações apresentadas neste artigo foram no sentido de contribuir com a otimização das ações, apenas, ao sugerir novas perspectivas didático-instrutivas a partir de uma educação ambiental (mais) crítica.

\section{REFERÊNCIAS}

Araújo, A. C. S.; Carvalho, A. C.; Nascimento, L. R. M.; Filgueiras, G. C.; \& Balieiro, A. M. (2019). Educação ambiental como elemento de apoio da sociedade civil organizada em prol do meio ambiente. In: Machado, F. S., \& Moura, A. S. (Org.). Educação, Meio Ambiente e Território. Ponta Grossa, PR: Atena.

Brasil. (1981). Lei no 6.938 de 1981: Dispõe sobre a Política Nacional do Meio Ambiente - PNMA.

Brasil. (1996). Lei de Diretrizes e Bases da Educação Nacional, LDB N. 9.394.

Brasil. (1999). Lei n 9.795 de 27 de abril de 1999, Política Nacional de Educação Ambiental.

Brasil. (1997). Ministério do Meio Ambiente dos Recursos Hídricos e da Amazônia Legal. Lei $\mathrm{n}$. 9.433: Política Nacional de Recursos Hídricos - PNRH. Brasília: Secretaria de Recursos Hídricos.

Brasil. (1998). Lei Federal № 9.605, de 12 de fevereiro de 1998. Dispõe sobre as sanções penais e administrativas derivadas de condutas e atividades lesivas ao meio ambiente, e dá outras providências. Disponível em http://www.planalto.gov.br/ccivil 03/leis/L9605.htm. Acesso em: 19/11/2020.

Brasil. (1999). Política Nacional de Educação Ambiental - PNEA. Lei 9.795/99.

Carvalho, A. C. (2018). La importancia de la educación y del capital humano como dinamizador del desarrollo en Brasil. Recuperado de: https://www.eumed.net/rev/atlante/2018/04/educaciondesarrollo-brasil.html 
Carvalho, A. C., \& Carvalho, D. F. (2017). Desenvolvimento Sustentável: passado, presente e perspectivas futuras. In: Vargas, J. T., \& Faria, D. S. (Org.). Textos Interdisciplinares: um olhar integrado sobre a Amazônia, o Brasil e o Conhecimento (1 $\stackrel{a}{\text { ed. }}$.). São Paulo, SP: Humanitas.

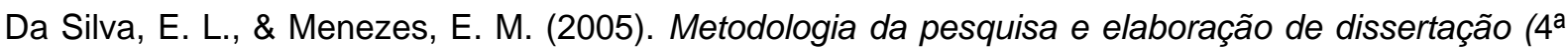
ed.). Florianópolis/SC: UFSC.

Dias, G. F. (2013). Educação ambiental: princípios e práticas (9ª ed.). São Paulo: Gaia.

Fischer, M. L., \& Lummertz, T. B. (2017). O Teatro Como Ferramenta de Promoção de Educação Ambiental. Revista Brasileira de Educação Ambiental. 12 (5), 56-72.

Guimarães, M. (2007). Educação ambiental: no consenso um embate? (5 $5^{\underline{a}}$ ed.). Campinas, SP: Papirus.

Lakatos, E. M., Marconi, M. A. (1991). Fundamentos de metodología científica. São Paulo: Atlas.

Layrargues, P. P, \& Lima, G. F. C. (2011). Mapeando as macro-tendências político-pedagógicas da educação ambiental contemporânea no Brasil. In VI Encontro "Pesquisa em Educação Ambiental" A Pesquisa em Educação Ambiental e a Pós-Graduação no Brasil. Ribeirão Preto/SP: Encontro.

Layrargues, P. P. (2012). Para onde vai à educação ambiental? O cenário político-ideológico da educação ambiental brasileira e os desafios de uma agenda política crítica contra-hegemônica. Revista Contemporânea de Educação, 7(14), 398-421.

Lei $n^{\circ} 9.795$ de 27 de abril de 1999. Dispõe sobre a educação ambiental, institui a Política Nacional de Educação Ambiental e dá outras providências. Recuperado de: http://www.planalto.gov.br/.

Loureiro, C. F. B. (2019). Educação ambiental: questão de vida. São Paulo: Cortez.

Lummertz, T. B., \& Fischer, M. L. (2017). O teatro como ferramenta de promoção de educação ambiental. Recuperado de: https://doi.org/10.34024/revbea.2017.v12.2488.

Meduar, O. (2015). Coletânea de legislação ambiental/Constituição federal (14. ed.). São Paulo/SP: Revista dos Tribunais.

Minayo, M. C. de S. (org.). (2001). Pesquisa Social. Teoria, método e criatividade (18 ${ }^{\mathrm{a}}$ ed.). Petrópolis/RJ: Vozes.

Ramos, E. C. (2001). Educação ambiental: origem e perspectivas. Recuperado de: http://www.scielo.br/scielo.php?script=sci_arttext\&pid=S0104-40602001000200012\&lng=en\&nrm=iso Reigota, M. (1994). O que é educação ambiental? Brasiliense, São Paulo.

Relatório de ações desenvolvidas (2012 a 2017). Benevides/PA: Asflora.

Santos, N. P. (2001). Educação Ambiental e ensino de educação artística nas escolas municipais de Santa Maria - RS [Monografia de Especialização, Universidade Federal de Santa Maria]. Repositório Institucional - Universidade Federal de Santa Maria.

Silva, F. W., \& Sammarco, Y. M. (2004). O Lazer \& Arte - Educação Ambiental.” In: Eunice Aita Isaia Kindel, Silva, F. W., \& Sammarco, Y. M. (Org.). "Educação Ambiental: vários olhares e várias práticas". Porto Alegre: Mediação.

Sorrentino, M., Trajber, R., Mendonça, P., \& Ferraro, J. L. (2005). Educação ambiental como política pública. Recuperado de: https://doi.org/10.1590/S1517-97022005000200010.

Spolin, V. (2008). Jogos teatrais: o fichário de Viola Spolin / Viola Spolin. São Paulo: Perspectiva. 